\title{
積分画像に基づくハーフトーニング
}

\section{Integral Image-Based Halftoning}

\author{
正会員 井上 光 ${ }^{\dagger}$, 原 健 二十, 浦 浜 喜 一
}

Kohei Inoue $^{\dagger}$, Kenji Hara ${ }^{\dagger}$ and Kiichi Urahama ${ }^{\dagger}$

\begin{abstract}
We propose a method for generating halftone images from grayscale images based on their integral images. The pixel values of a halftone image are determined so that the errors between the integral image of the halftone image and that of the grayscale image are minimized.
\end{abstract}

キーワード：ハーフトーニング，グレースケール画像，積分画像

\section{1. ま え がき}

ハーフトーニングは古くから写真複写などに利用されて おり，その方法としては，濃度パターン法，ディザ法，誤差 拡散法がよく知られている11. 本論文では, グレースケール 画像とそのハーフトーン画像の間の誤差を, 両者の積分画 像 (integral image ${ }^{2)}$ ) を用いて評価し, 積分画像間の誤差 が小さくなるようなハーフトーン画像を生成する方法を提 案し, 誤差拡散法の代表的手法である Burkes 法 ${ }^{3)}$, Stucki 法 $^{4)}$, Floyd-Steinberg 法 ${ }^{5}$ との比較実験を行い, 提案手法 の有効性を示す。

\section{2. 提 案 手 法}

$m$ 行 $n$ 列の画素で構成されるグレースケール画像を $f=\left[f_{i j}\right], i=1, \ldots, m ; j=1, \ldots, n$ とする.ここで $f_{i j} \in\{0, \ldots, 255\}$ は画素 $(i, j)$ の值である. $f$ の積分画 像 ${ }^{2)} F=\left[F_{i j}\right]$ とすると，

$$
F_{i j}=\sum_{k=1}^{i} \sum_{l=1}^{j} f_{k l}
$$

である. 一方, $f$ のハーフトーン画像を $g=\left[g_{i j}\right]$ とする. ここで $g_{i j} \in\{0,255\}$ である. $g$ の積分画像を $G=\left[G_{i j}\right]$ とする。本論文では, 積分画像 $F, G$ 間の誤差が小さくなる ようなハーフトーン画像 $g$ を生成する方法を提案する。す なわち, $g_{i j}$ の值を, ラス夕走査の順に次式で決めていく.

$$
g_{i j}= \begin{cases}0, & \text { if }\left|F_{i j}-G_{i j}^{B}\right|<\left|F_{i j}-G_{i j}^{W}\right| \\ 255, & \text { otherwise }\end{cases}
$$

2013 年 2 月 19 日受付, 2013 年 3 月 26 日採録

†九州大学 大学院芸術工学研究院 コミュニケーションデザイン科学部門

(₹ 815-8540 福岡市南区塩原 4-9-1, TEL 092-553-4512)

$\dagger$ Department of Communication Design Science, Faculty of Design, Kyushu University

(4-9-1, Shiobaru, Minami-ku, Fukuoka-shi, 815-8540 Japan)
ここで, $G_{i j}^{B}$ は $g_{i j}=0$ とした場合の $G_{i j}$ の值を表し, $G_{i j}^{W}$ は $g_{i j}=255$ とした場合の $G_{i j}$ の值を表す.

\section{3. 実 験 例}

図 1 にハーフトーニングの結果を示す. 1 番左の列の 3 枚の画像は元のグレースケール画像であり, 各画像の画素 数は $512 \times 512$ である. 2-5 列に，それぞれ Burkes 法3), Stucki 法 ${ }^{4}$, Floyd-Steinberg (F.-S.) 法 ${ }^{5)}$, 提案手法によ る結果を示す。2-4 列の画像の作成には, Jasc Paint Shop Pro (ver. 7.04) を用いた。提案手法により，積分画像間 の誤差が小さくなることを示すために，図 1 の 1 番上の 画像における各ハーフトーン画像の積分画像と入力画像の 積分画像との差の絶対值 $\left|F_{i j}-G_{i j}\right|$ を図 2 に示す。横軸 は $j$ であり, $i=256$ とした. Burkes 法 ${ }^{3)}$, Stucki 法 ${ }^{4)}$, F.-S. 法 ${ }^{5)}$, 提案手法をそれぞれ実線, 破線, 細かい破線, 点線で示している. Burkes 法 ${ }^{3)}$, Stucki 法 ${ }^{4)}$, F.-S. 法5)で は，jの值が増加するにつれて誤差も増加しているのに対 して, 提案手法では, 誤差は小さく, $j$ の増加に伴う誤差 の増加もみられない.これら 4 手法の平均絶対誤差はそれ ぞれ $2.22 \times 10^{6}, 2.05 \times 10^{6}, 1.97 \times 10^{6}, 69.8$ であり，提 案手法による誤差が最も小さい.

次に, 元のグレースケール画像の再現性を定量的に評価す るために, 各画像の縦と横をそれぞれ $2^{p}(p=0,1, \ldots, 8)$ 等分して, 各画像をブロック分割し, 各ブロック内をその ブロック内の平均画素值で塗った画像を生成する。このよ うにして生成した画像の例を図 3 に示す。1 番上の行は元 画像のブロック分割画像であり，2 行目以降にBurkes 法3), Stucki 法 ${ }^{4)}$, F.-S. 法 ${ }^{5)}$, 提案手法によるハーフトーン画像の ブロック分割画像を順に並べている。ブロック分割画像を 用いて，ピーク信号対雑音比 (peak signal-to-noise ratio: PSNR) を求めた結果を図 4 に示す。縦軸はPSNR であ り, 横軸は $p$ である。実線に+印はBurkes 法3)を表し, 破 


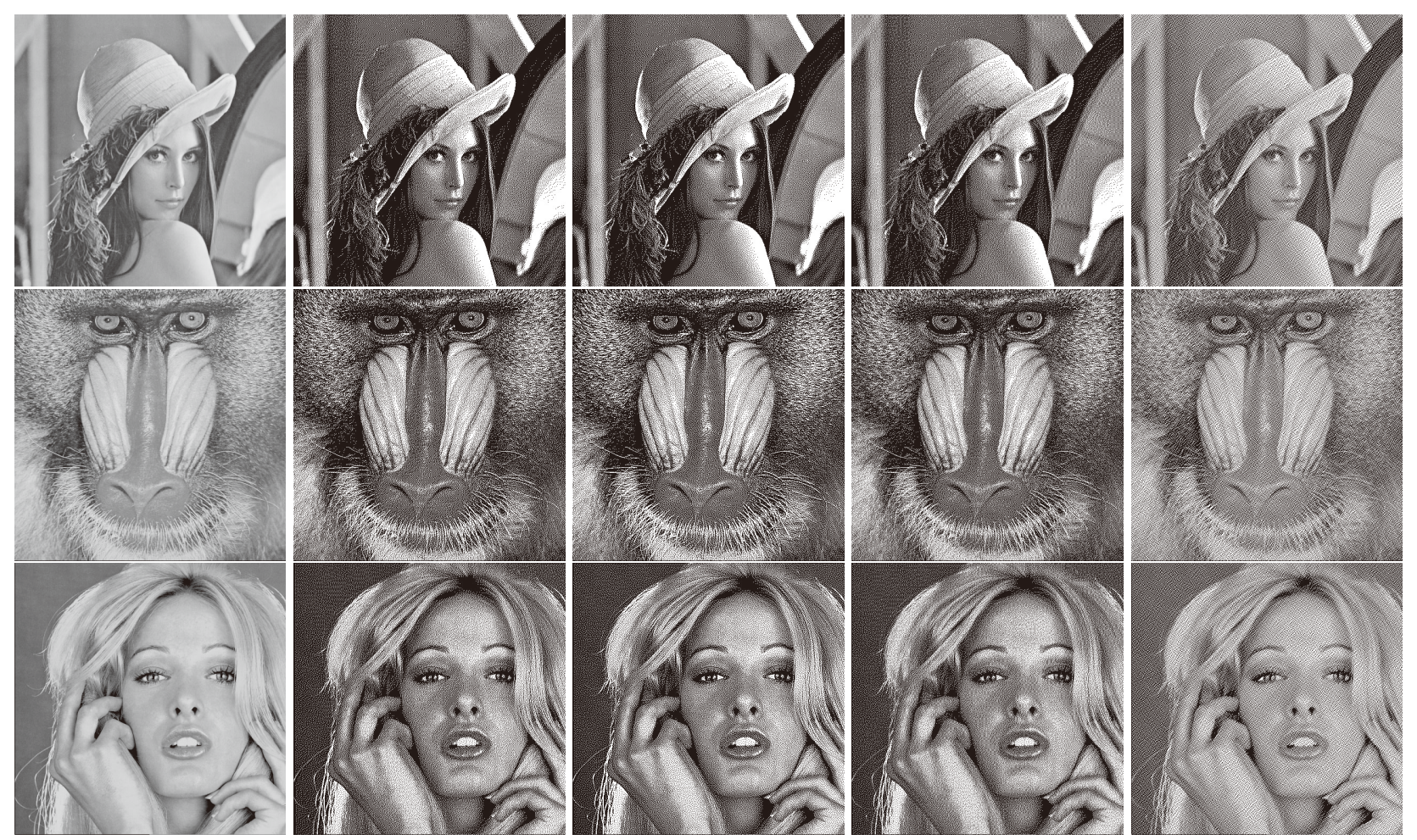

図 1 ハーフトーニングの結果: (1 列目) 元画像, (2 列目) Burkes 法 ${ }^{3)}$, (3 列目) Stucki 法 ${ }^{4}$, (4 列目) FloydSteinberg 法 $^{5}$, , (5 列目) 提案手法

Results of halftoning: (1st column) original images, (2nd column) Burkes ${ }^{3)},\left(3 \mathrm{rd}\right.$ column) Stucki $\left.{ }^{4}\right),(4$ th column) Floyd-Steinberg ${ }^{5)}$, and (5th column) the proposed.

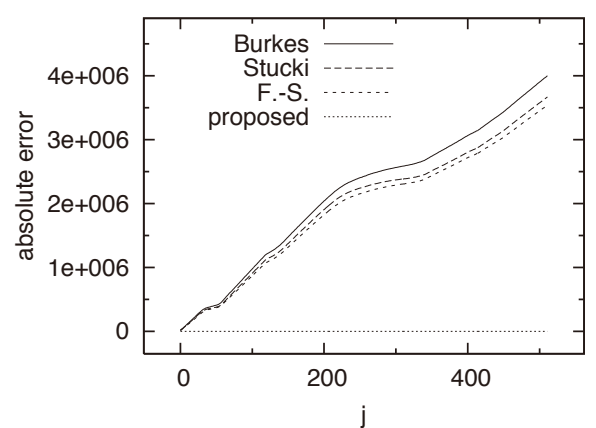

図 2 絶対誤差

Absolute error.

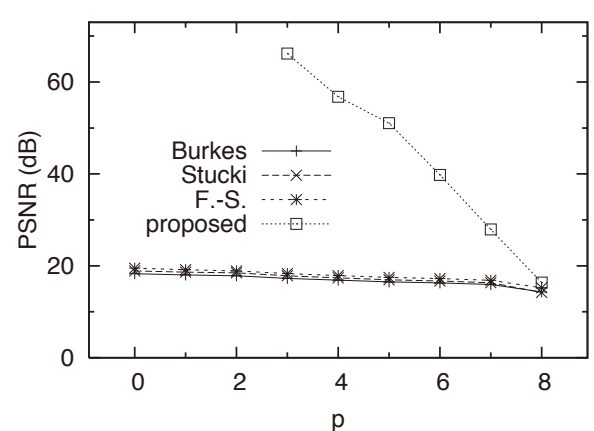

図 4 PSNR PSNR.
線に×印はStucki 法4)を表し, 細かい破線に*印は F.-S. 法5)を表し，点線に口印は提案手法を表す。提案手法では, $p=0,1,2$ に扔いて平均 2 乗誤差が 0 に近い值になったた め, その部分は表示していない. 従来手法では, PSNR 值 はF.-S. 法 ${ }^{5}$ が最も高く, 次がStucki 法4)であり, Burkes 法3)が最も低いが，それらの差は小さい。提案手法は，こ れら従来手法よりも高いPSNR 值を示した。

\section{4. むすび}

グレースケール画像とそのハーフトーン画像の積分画像を 考え, 積分画像間の誤差が小さくなるようにハーフトーン画 像を構成するハーフトーニング法を提案し, 従来の Burkes 法3), Stucki 法4), Floyd-Steinberg 法5)よりも誤差が小さ いハーフトーン画像が得られることを実験で示した。また,
元のグレースケール画像の再現性をピーク信号対雑音比 (PSNR)によって評価し, 提案手法によって, 元画像の再 現性の高いハーフトーン画像が得られることも確認した。 カラー画像への拡張と逆ハーフトーニング法の開発が今後 の課題である。

\section{〔文献〕}

1）ディジタル画像処理, CG-ARTS 協会 (2006)

2) P. Viola and M. J. Jones: "Robust real-time face detection", IJCV, 57, 2, pp. 137-154 (2004)

3) http://www.efg2.com/Lab/Library/ImageProcessing/DHALF.TXT

4) P. Stucki: "MECCA - a multiple-error correcting computation algorithm for bilevel image hardcopy reproduction", Research Report RZ1060, IBM Research Laboratory (1981)

5) R. W. Floyd and L. Steinberg: "An adaptive algorithm for spatial grey scale", Proc. the Society of Information Display, 17, pp. 75-77 (1976) 


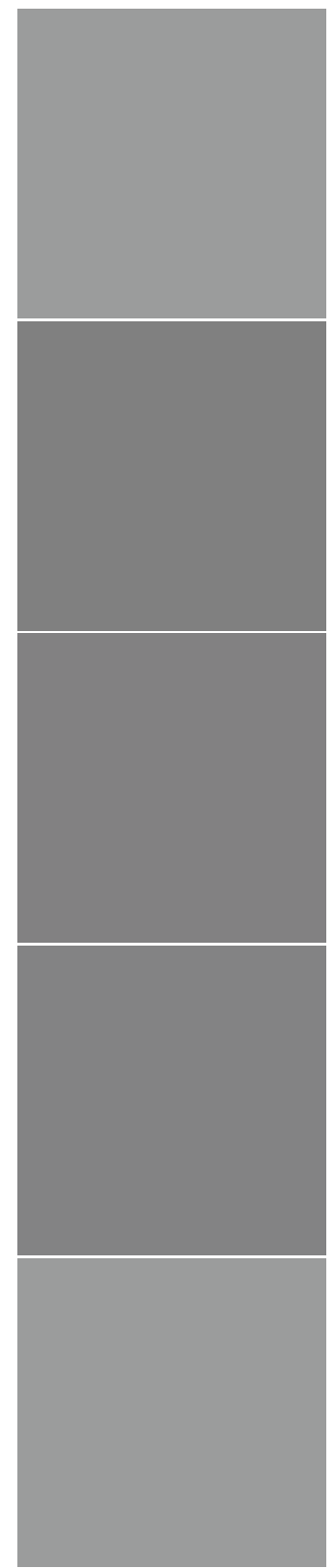

$p=0$

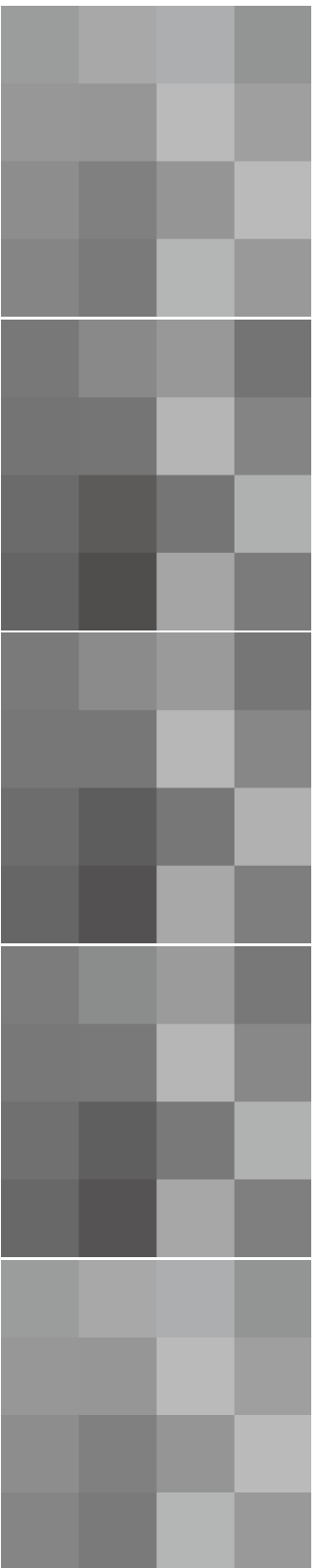

$p=2$

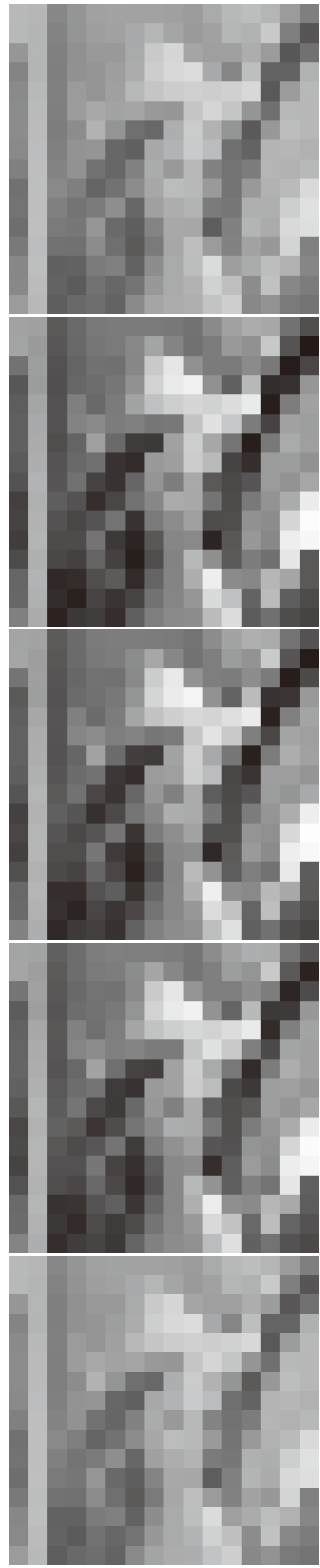

$p=4$

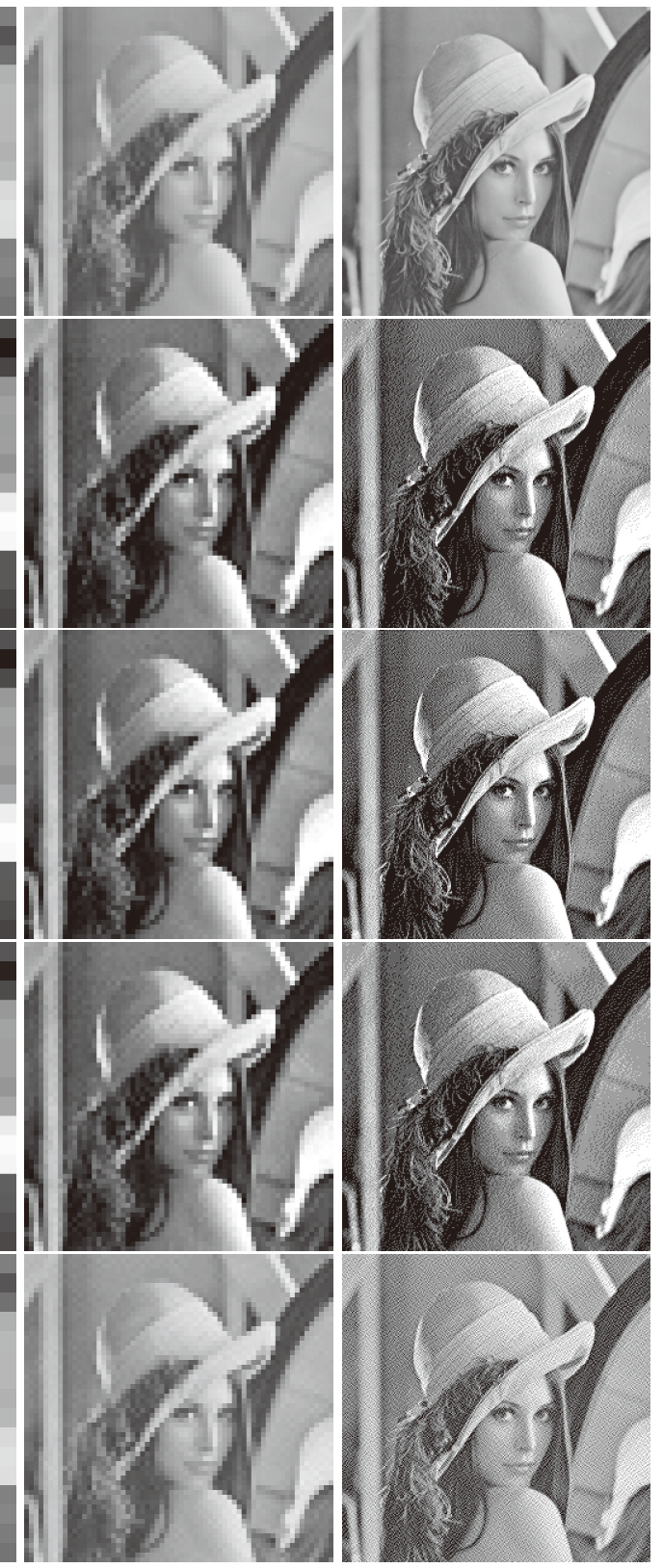

$p=6$

$p=8$

図 3 ブロック分割画像の例: (1 行目) 元画像, (2 行目) Burkes 法 ${ }^{3)}$, (3 行目) Stucki 法4), (4 行目) Floyd-Steinberg 法 $^{5)}$, (5 行目) 提案手法

Block-divided images: (1st row) original images, (2nd row) Burkes ${ }^{3)}$, (3rd row) Stucki ${ }^{4}$, (4th row) FloydSteinberg ${ }^{5)}$, and (5th row) the proposed.

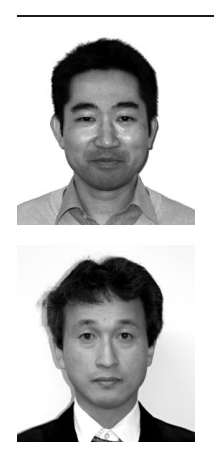

井上光光平 1996 年, 九州芸術工科大学画像設計 学科卒業. 2000 年, 同大学大学院博士後期課程修了. 現 在, 九州大学大学院芸術工学研究院助教. パターン認識, 画像処理, コンピュータビジョンに関する研究に従事. 正会員.

原係健二 1989 年, 京都大学大学院工学研究科 修士課程修了。同年, 武田薬品工業 (株) 入社, 1991 年, 福岡県工業技術センター入所. 2001 年，東京大学生産技 術研究所協力研究員. 現在, 九州大学大学院芸術工学研 究院准教授. 博士 (工学).コンピュータビジョン, 画像 処理に関する研究に従事.

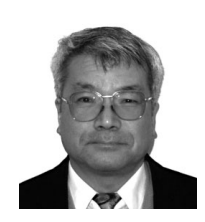

浦浜喜いち 1980 年, 九州大学大学院工学研究科 博士後期課程修了. 同年, 同大学助手. 1989 年, 九州工 業大学助教授. 現在, 九州大学大学院芸術工学研究院教 授. パターン認識, 画像情報処理の研究に従事. 